\title{
RESEARCH METHODS FOR THE EVALUATION OF THE RELEVANCE OF APPLICATION ORIENTED LABORATORY WEAR TESTS
}

\author{
K. Valtonen ${ }^{1 *}$, V. Ratia ${ }^{1,2}$, V.-T. Kuokkala ${ }^{1}$ \\ ${ }^{1}$ Tampere Wear Center, Tampere University, P.O. Box 589, 33014 Tampere University, Finland \\ ${ }^{2}$ VTT Technical Research Centre of Finland Ltd., P.O. Box 1000, FI-02044 VTT, Finland
}

\begin{abstract}
In this work, different research methods and test procedures were examined and compared in order to have a better understanding of the relevance of various application oriented laboratory wear tests relative to the inservice performance of the steels in mining conditions. One of the important results of this study is that quite different wear events can be compared, when the wear rates are presented as the mass loss of the sample divided by the wear area, contact time, and density of the material. However, this kind of information is commonly very difficult to obtain for the in-service samples, and thus normalizing of the results with a reference material is often an easier route. On the other hand, thorough characterization and comparison of the wear surfaces and deformations is essential for the confirmation of the similarity of the wear mechanisms in different cases or different tests. In the studied case of the wear plate of a dumper truck body, several test methods were needed for the experimental simulation of the complex wear environment in the haulage of minerals.
\end{abstract}

Keywords: Wear testing; abrasion; impact wear; steel; mining

*Corresponding author: K. Valtonen (kati.valtonen@tuni.fi)

\section{INTRODUCTION}

Numerous standardized wear tests, and even many more non-standardized laboratory wear tests, are in common use to screen materials for their wear resistance. However, there are not too many studies that try to evaluate the relevance of the laboratory wear experiments for the assessment of the in-service performance of materials in high stress abrasion and impact wear conditions [1,2]. In addition, the simulation of in-service wear environments in the laboratory scale is challenging even with known conditions: in the planning of the test procedures, the effect of many variables, such as the contact conditions, abrasive properties, and environment on the active wear mechanism(s) and the resulting wear rate must be carefully taken into consideration. However, the interpretation of the laboratory test results is normally easier and the repeatability of the tests is better those that of the complex and often much more expensive in-service tests.

There are various ways to present the wear test results. For example, Blau [3] found over sixty different ways of presenting the wear test results from the papers published in the proceedings of a single Wear of Materials conference. The most typical ways to express wear test data were the mass or volume loss as such, or normalized by test parameters such as test time, traveled distance, or amount of the used abrasive [3]. Blau [3] also criticized the 


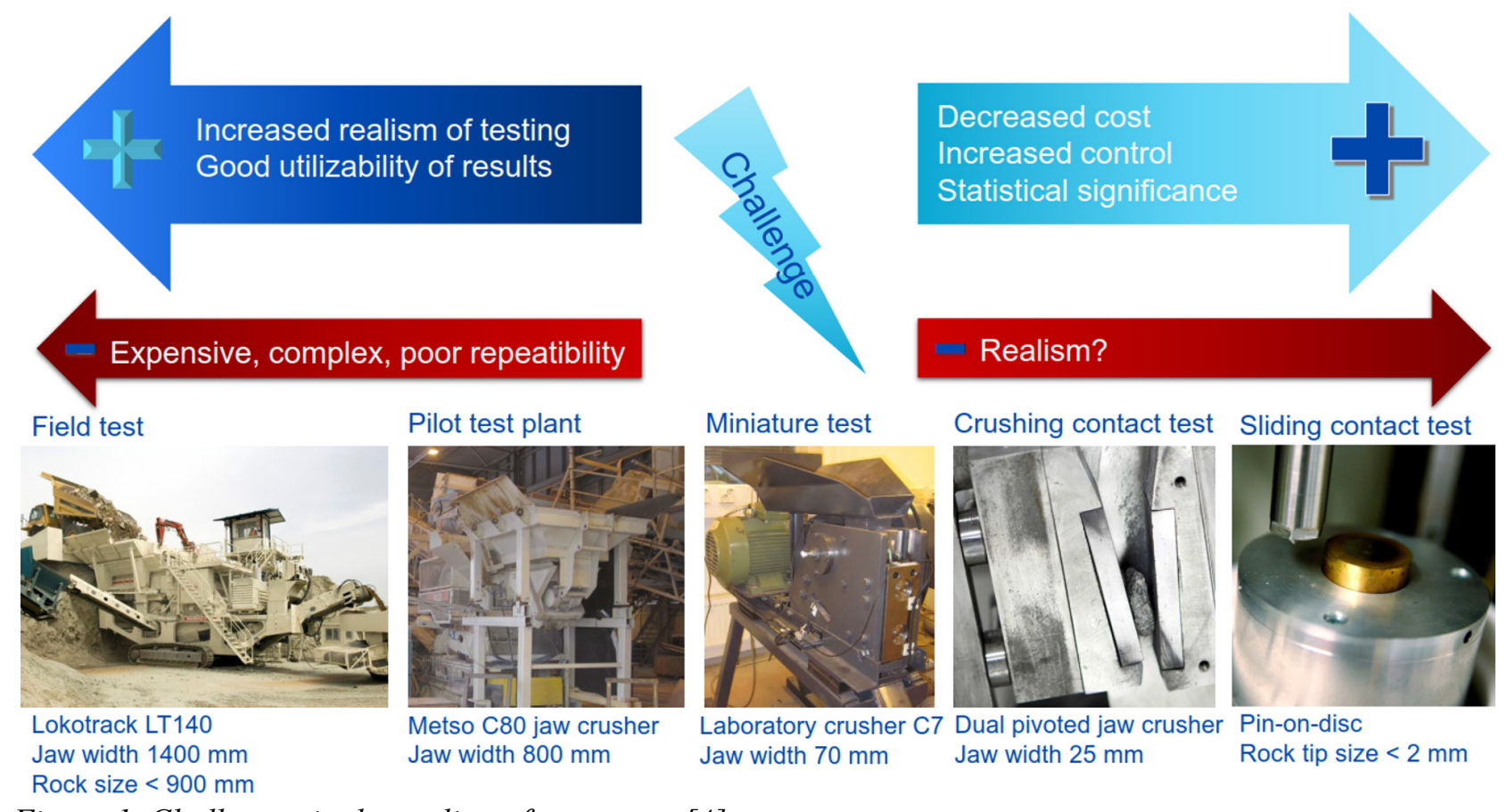

Figure 1. Challenges in the scaling of wear tests [4].

common trend of presenting the wear results assuming that the wear rate has been steady throughout the test. In abrasion, for example, fracturing of the abrasive particles and embedment in the wear surface tend to reduce the wear rate. Thus, a running-in period may have a marked effect on the total wear rate of the test.

Figure 1 uses a jaw crusher as an example of the challenges related to the different scales of wear tests. On one hand, well-planned fullscale field tests give directly utilizable results for the in-service use, but they are usually expensive and practically non-repeatable, i.e., performing two, let alone more identical field tests is practically impossible since the operational and environmental conditions tend to vary too much even between nominally similar cases. On the other hand, it is neither so easy to determine how well the laboratory wear tests represent the in-service conditions. In general, the simpler the test the easier it is to control and repeat, but for example in the case of a jaw crusher, it is clear that a simple sliding contact test does not reproduce the complex wear environment and the high loads typical to a full-scale jaw crusher. Thus, when planning a laboratory-scale wear test, it is important to know the prevailing wear environment that the test tries to simulate for the test results be a usable for example in a materials selection process.

In this study, three abrasive and impactabrasive wear test methods were used to study the wear behavior of four steel grades and to simulate the wear in a dumper truck body used to haul minerals in a mine. The wear test results were published earlier [5], but the publication did not include a comparison to the in-service conditions. Moreover, this study serves as an example how the assessment of selected laboratory wear tests' ability to mimic the real wear conditions could be done.

\section{MATERIALS AND METHODS}

Table 1 lists the studied steels and their main properties related to wear, including the initial bulk hardness, yield strength $\left(\mathrm{R}_{\mathrm{p} 0.2}\right)$, ultimate tensile strength $\left(\mathrm{R}_{\mathrm{m}}\right)$, elongation (A5), and impact toughness at $-40^{\circ} \mathrm{C}$. The studied dumper truck body wear plate was made of the 400HB steel. 
Table 1. Typical mechanical properties and nominal compositions of the tested steels.

\begin{tabular}{lcccc}
\hline & $\mathrm{S} 355$ & $400 \mathrm{HB}$ & $450 \mathrm{HB}$ & $500 \mathrm{HB}$ \\
\hline Hardness range, HV10 & $161 \pm 2$ & $415 \pm 13$ & $489 \pm 9$ & $513 \pm 5$ \\
\hline $\mathrm{R}_{\mathrm{p} 0.2\left[\mathrm{~N} / \mathrm{mm}^{2}\right]}$ & 355 & 1000 & 1200 & 1250 \\
\hline $\mathrm{R}_{\mathrm{m}}\left[\mathrm{N} / \mathrm{mm}^{2}\right]$ & $430-530$ & 1250 & 1450 & 1600 \\
\hline $\mathrm{A} 5[\mathrm{~min} \%]$ & 24 & 10 & 8 & 8 \\
\hline Impact toughness $-40^{\circ} \mathrm{C}[\mathrm{J}]$ & 40 & 30 & 30 & 30 \\
\hline $\mathrm{C}[\mathrm{wt} \%]$ max. & 0.12 & 0.25 & 0.26 & 0.30 \\
\hline $\mathrm{Si}[\mathrm{wt} \%]$ max. & 0.03 & 0.80 & 0.80 & 0.80 \\
\hline $\mathrm{Mn}[\mathrm{wt} \%]$ max. & 1.5 & 1.7 & 1.7 & 1.7 \\
\hline $\mathrm{Cr}[\mathrm{wt} \%]$ max. & - & 1.5 & 1 & 1 \\
\hline $\mathrm{Ni}[\mathrm{wt} \%]$ max. & - & 1 & 1 & 1 \\
\hline $\mathrm{Mo}[\mathrm{wt} \%]$ max. & - & 0.5 & 0.5 & 0.5 \\
\hline $\mathrm{B}[\mathrm{wt} \%]$ max. & - & 0.005 & 0.005 & 0.005 \\
\hline & & & &
\end{tabular}

The wear behavior of the 400HB steel wear plate used in the dumper truck body was simulated using the uniaxial crusher, crushing pin-on-disc, and impeller-tumbler wear test devices. The operation history of the in-service wear plate was unfortunately not known. Figure 2 shows the schematics of the test devices and Table 2 lists the main test parameters used in each of the tests.

In the uniaxial crusher tests [5], 4-6.3 mm Sorila granite was crushed with a cylindrical sample $(\varnothing 36 \mathrm{~mm})$ against the tool steel bottom plate of a rubber cup using the normal force of $53 \mathrm{kN}$. The granite was replaced automatically after every crushing cycle in the 900 cycle tests.
In the crushing pin-on-disc tests [5], similar sample pins as used in the uniaxial crushing tests were compressed with a $200 \mathrm{~N}$ force against a $2-10 \mathrm{~mm}$ gravel bed rotating on top of the disc made of a similar steel as the sample. The total contact time in the tests was $20 \mathrm{~min}$, consisting of alternating five seconds of crushing contact and 2.5 seconds of free rotation.

The impeller-tumbler impact abrasive wear tester [5] was used to crush 10-12.5 mm granite gravel with three rotating $75 \times 25 \times 5 \mathrm{~mm}$ plate samples. One of the samples in each test was a 400HB reference sample. The samples were rotating at a $60^{\circ}$ angle at $700 \mathrm{rpm}(7.7 \mathrm{~m} / \mathrm{s}$ tip speed) in the same direction as the tumbler

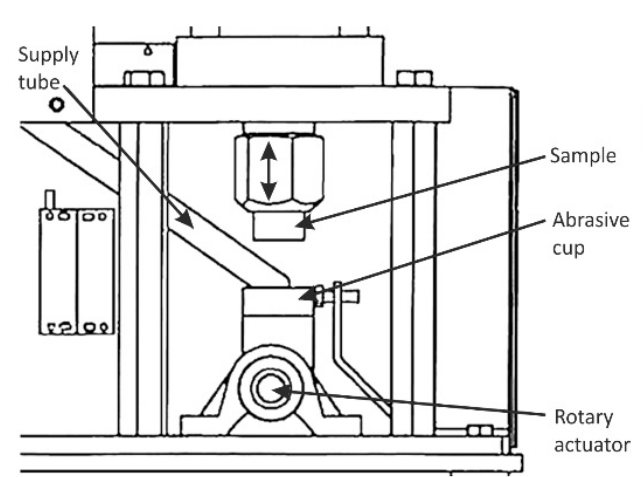

a)

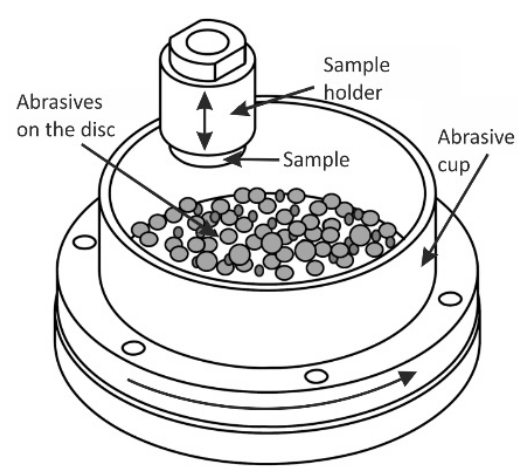

b)

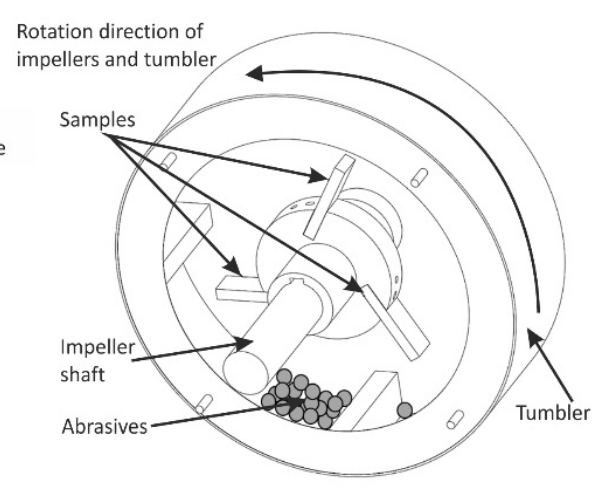

c)

Figure 2. Test methods: a) uniaxial crusher, b) crushing pin-on-disc, and c) impeller-tumbler. 
Table 2. Test parameters used in the wear tests.

\begin{tabular}{lccc}
\hline $\begin{array}{l}\text { Test } \\
\text { method }\end{array}$ & $\begin{array}{c}\text { Uniaxial } \\
\text { crusher }\end{array}$ & $\begin{array}{c}\text { Crushing } \\
\text { pin-on- } \\
\text { disc }\end{array}$ & $\begin{array}{c}\text { Impeller- } \\
\text { tumbler }\end{array}$ \\
\hline $\begin{array}{l}\text { Contact } \\
\text { time [min] }\end{array}$ & 28.5 & 20 & $4 \times 15$ \\
\hline $\begin{array}{l}\text { Wear area } \\
{\left[\mathrm{mm}^{2}\right]}\end{array}$ & 1018 & 1018 & 1200 \\
\hline $\begin{array}{l}\text { Sample size } \\
\text { [mm] }\end{array}$ & $\varnothing 36 \times 35$ & $\varnothing 36 \times 35$ & $\begin{array}{c}75 \times 25 \times \\
10\end{array}$ \\
\hline $\begin{array}{l}\text { Normal } \\
\text { force [N] }\end{array}$ & 53000 & 200 & \\
\hline $\begin{array}{l}\text { Counterpart } \\
\text { Sample }\end{array}$ & Tool steel & $\begin{array}{c}\text { Similar to } \\
\text { pin }\end{array}$ & \\
\hline $\begin{array}{l}\text { Samgle [ }] \\
\text { abrasive }\end{array}$ & Sorila granite & $\begin{array}{c}\text { Sorila } \\
\text { granite }\end{array}$ & $\begin{array}{c}\text { Sorila } \\
\text { granite }\end{array}$ \\
\hline $\begin{array}{l}\text { Abrasive } \\
\text { size [mm] }\end{array}$ & $4-6.3$ & $2-10$ & $10-12.5$ \\
\hline $\begin{array}{l}\text { Amount of } \\
\text { abrasive in } \\
\text { one test } \\
\text { cycle [g] }\end{array}$ & 30 & 500 & 900 \\
\hline Running-in & 100 & 20 min & 15 min \\
\hline
\end{tabular}

was rotating at $30 \mathrm{rpm}$. Each test included four 15 minute test cycles, with the gravel changed after each cycle.

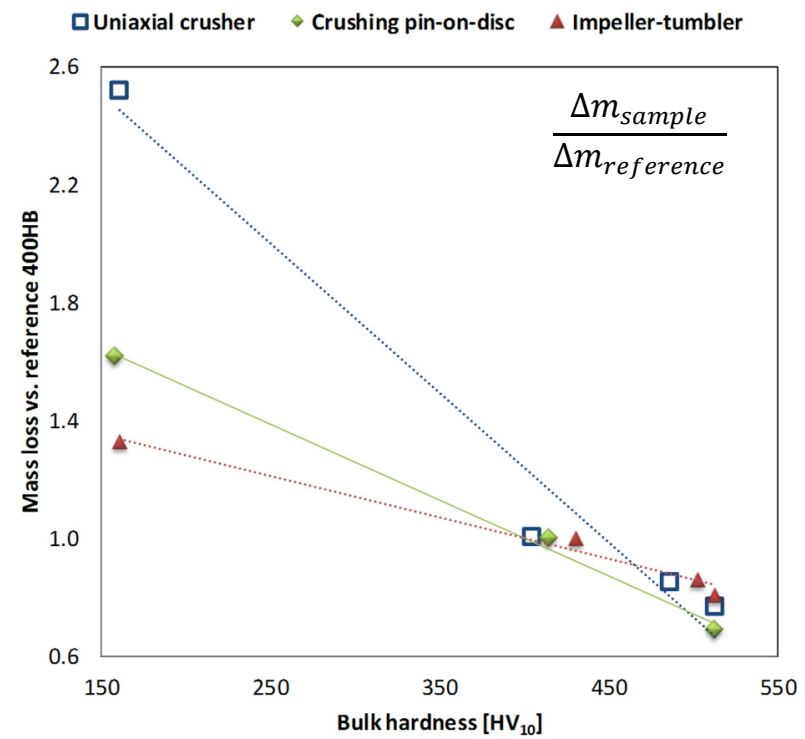

a)
The wear surfaces were characterized using Zeiss ULTRAplus field emission gun scanning electron microscope (SEM). Optical microscope Nikon Eclipse MA 100 was used for the cross-sectional analysis of the wear surfaces. The etching was made with $4 \%$ Nital. The thick rust layer on top of the dumper truck body wear plate was partly removed with $10 \%$ USF 175 acidic detergent in an ultrasound cleaner.

\section{RESULTS AND DISCUSSION}

The three quite different wear test methods were compared either by normalizing the test results by the corresponding data obtained for the reference material, or by determining the wear rates as the mass loss of the sample divided by the wear area, contact time, and density of the steel, as shown in Figure 3. Both of these evaluation methods, which complement each other, have also earlier been used in the comparison of the laboratory and field wear tests $[6,7]$. Although the normalized mass loss results presented in Figure 3a do not show the differences between the test methods too well, the small differences between the steel grades can be seen better.

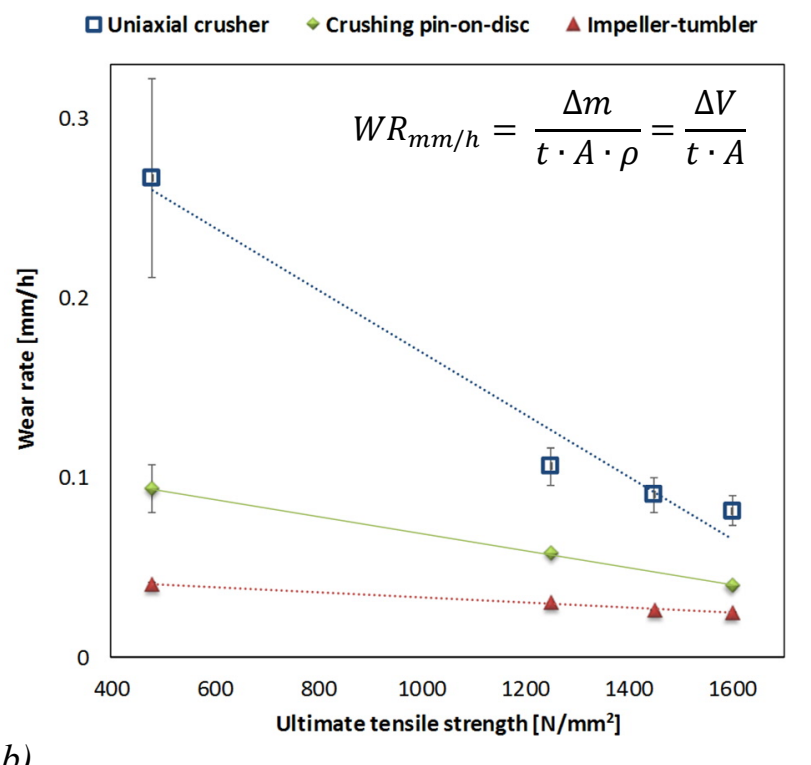

b)

Figure 3. Wear test results of the studied steels a) mass loss normalized by the 400HB results vs. hardness and b) wear rate $\left(W R_{m m / h}\right)$ vs. $R_{m}$. The error bars present the standard deviation. 
For example, in the impeller-tumbler tests with a reference sample, the normalization largely cancels out the small differences between the granite loads used in the tests, and thus shows more reliably the differences between the wear resistant steel grades. Figure $3 b$, in turn, shows better the differences in the wear rates between the test methods. All methods arranged the steels similarly, but the uniaxial crusher clearly produced the highest wear rates. Also, the standard deviation of the results given by the uniaxial crusher method was the highest. Large burrs were formed especially in the S355 structural steel samples due to heavy plastic deformation during the uniaxial crusher tests.

Because in the examined case the operation history of the dumper body wear plate was

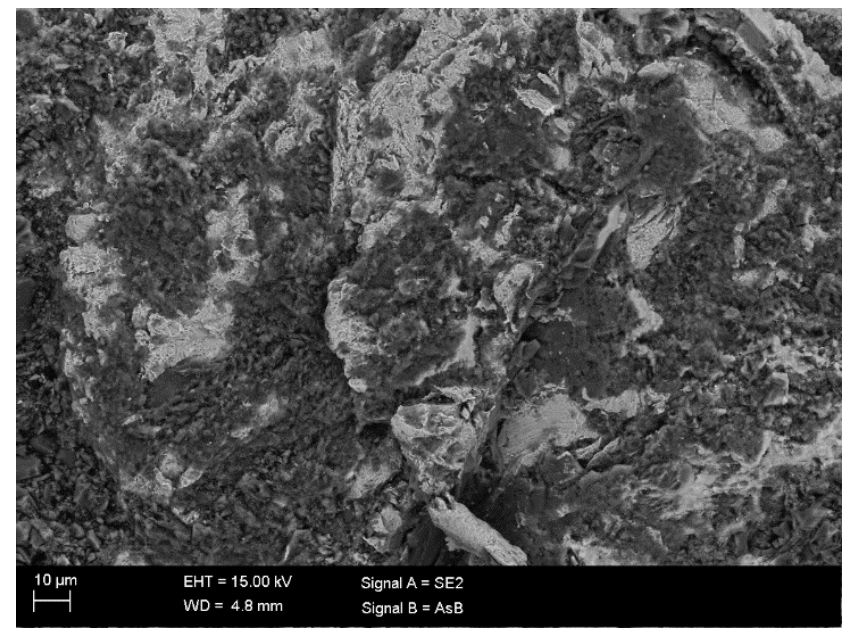

a)

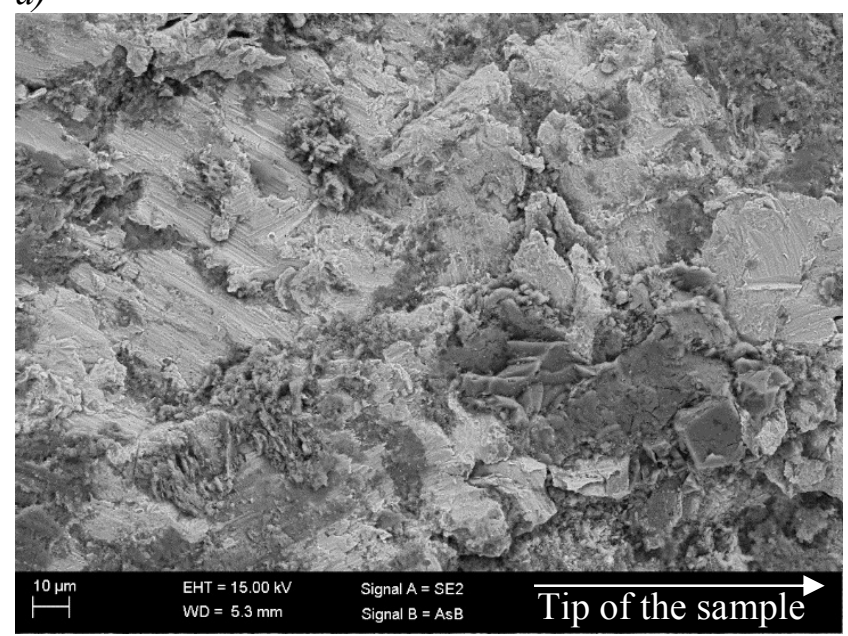

c)

Figure 4. SEM images from the wear surfaces of the 400HB steel samples tested with a) uniaxial crusher, b) crushing pin-on-disc, and c) impeller-tumbler and d) from the in-service dumper truck wear plate. unknown, the evaluation of the in-service wear mechanisms and their comparison to the laboratory wear tests was possible only through careful characterization of the wear surfaces and the deformed layers from the polished cross-sections. In the appearance and roughness of the wear surfaces formed in the different steels, clear differences were observed. In general, the surface roughness and the amount of embedded abrasive decreased with increasing initial hardness of the steel. Figure 4 presents examples of the 400HB steel wear surfaces tested with different methods compared to the in-service sample. The most distinct scratches were seen on the crushing pin-on-disc tested surfaces, which, on the other hand, exhibited the lowest

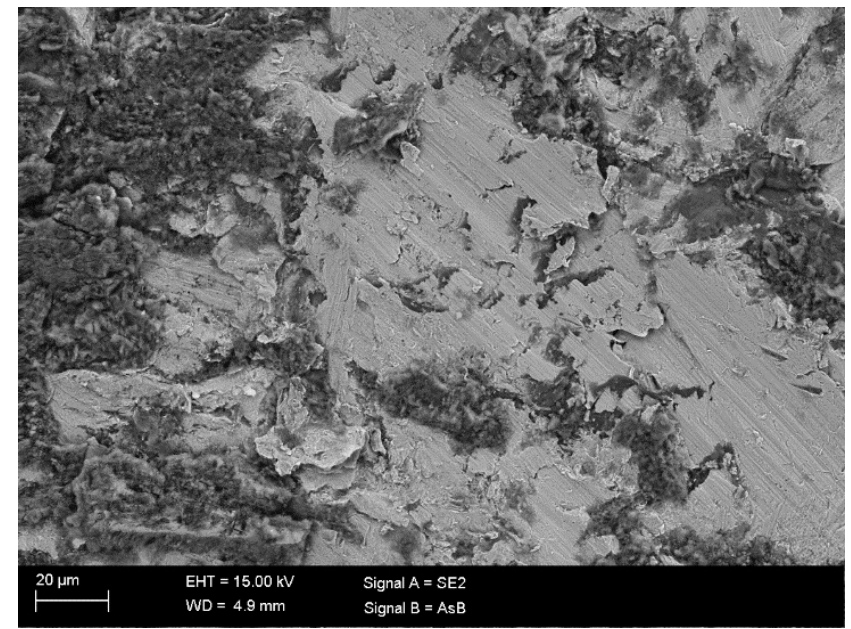

b)

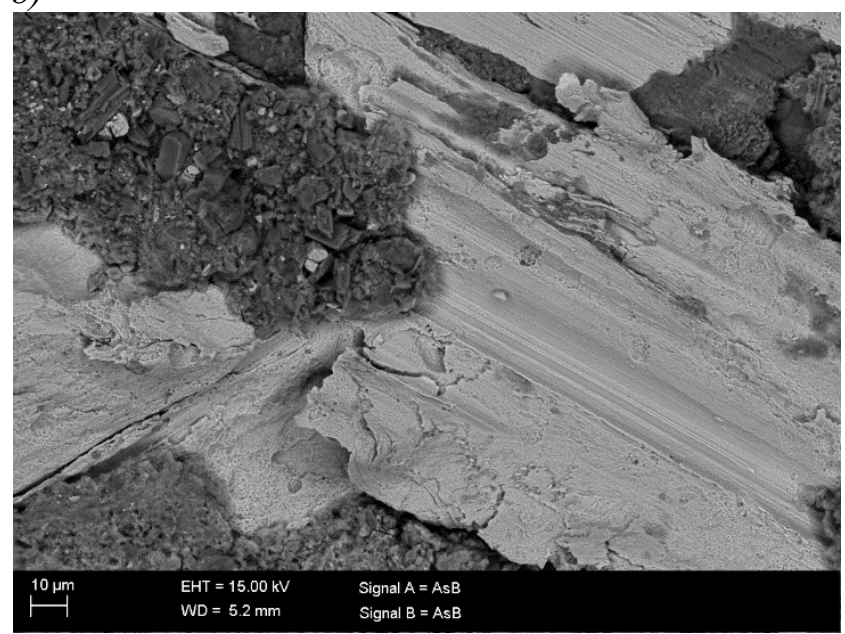


surface roughness values. The surface roughness was highest in the dumper truck wear plate, which had also bent due to the heavy impacts by large rocks. Moreover, the scratches produced by cutting and ploughing by the rocks were much deeper and longer in the in-service sample than in the wear tested samples, and also signs of surface fatigue could be observed in the in-service sample.

The cross-sections of the dumper truck wear plate contained certain features of all laboratory-tested samples. For example, Fig. 5 shows the formation of subsurface adiabatic shear bands (ASB), indicating heavy impacts
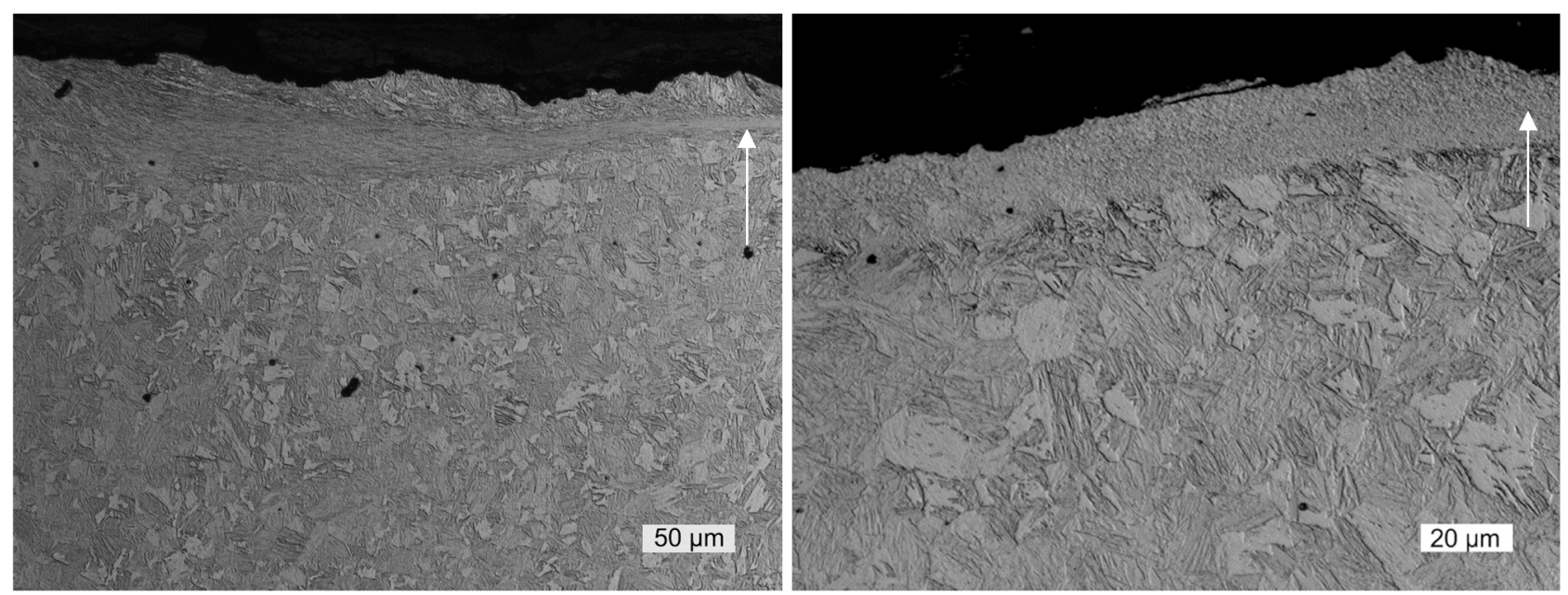

a)

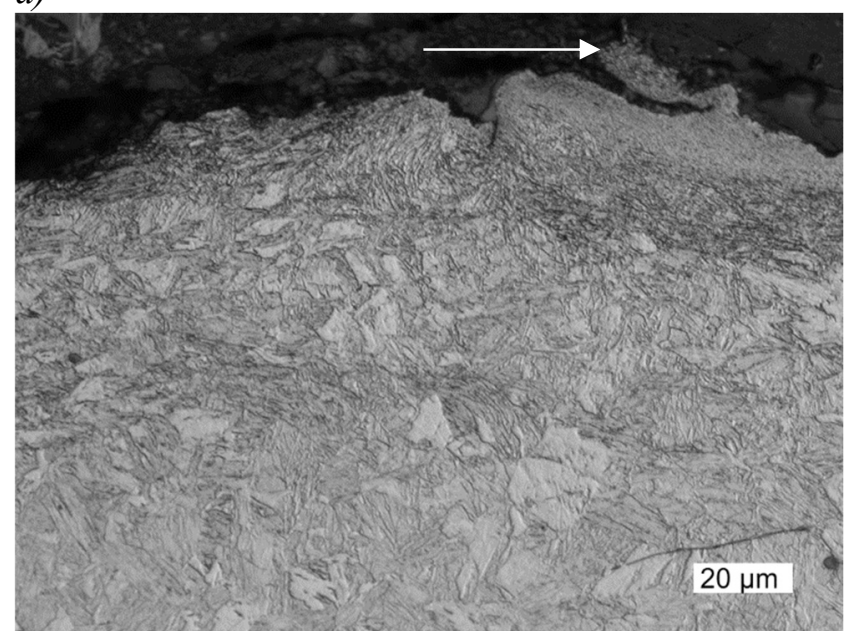

b)
[8]. This type of ASB's were also found in the tips of the $400 \mathrm{HB}$ and $500 \mathrm{HB}$ impellertumbler samples (Fig. 6c). In some parts of the dumper truck wear plate, the wear surface was heavily deformed with extensive cracking and delamination (Fig. 5c), similar to the uniaxial crusher and crushing pin-on-disc tests (Fig. 6). However, the thick white layers, which are sometimes found to form on the wear surfaces during high-stress abrasion [6], were observed only on the wear surfaces of the wear plate. Thus, a test method with more extensive cutting would probably be needed to complement the current test methods.

c)

Figure 5. Optical micrographs of the wear surface cross-section of the dumper body wear plate showing a) a subsurface adiabatic shear band, b) a white layer, and c) delamination, as indicated by the arrows in each of the images. 

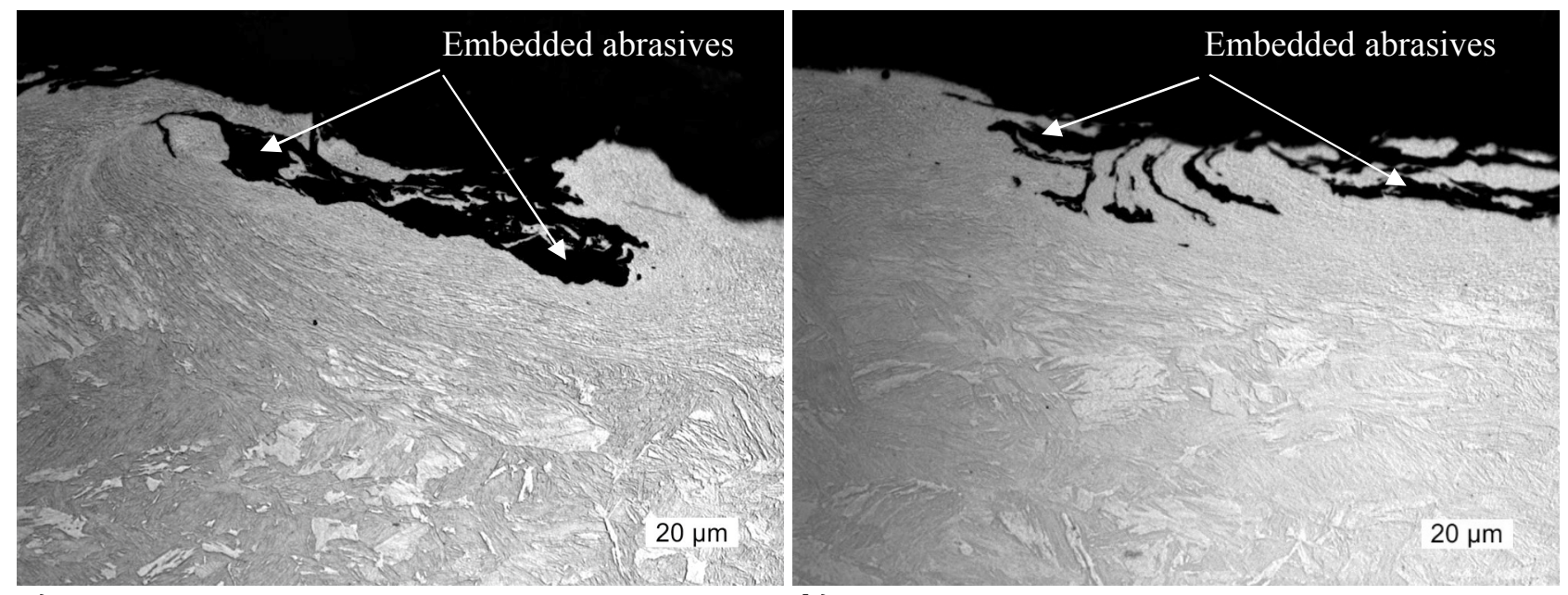

a)

b)
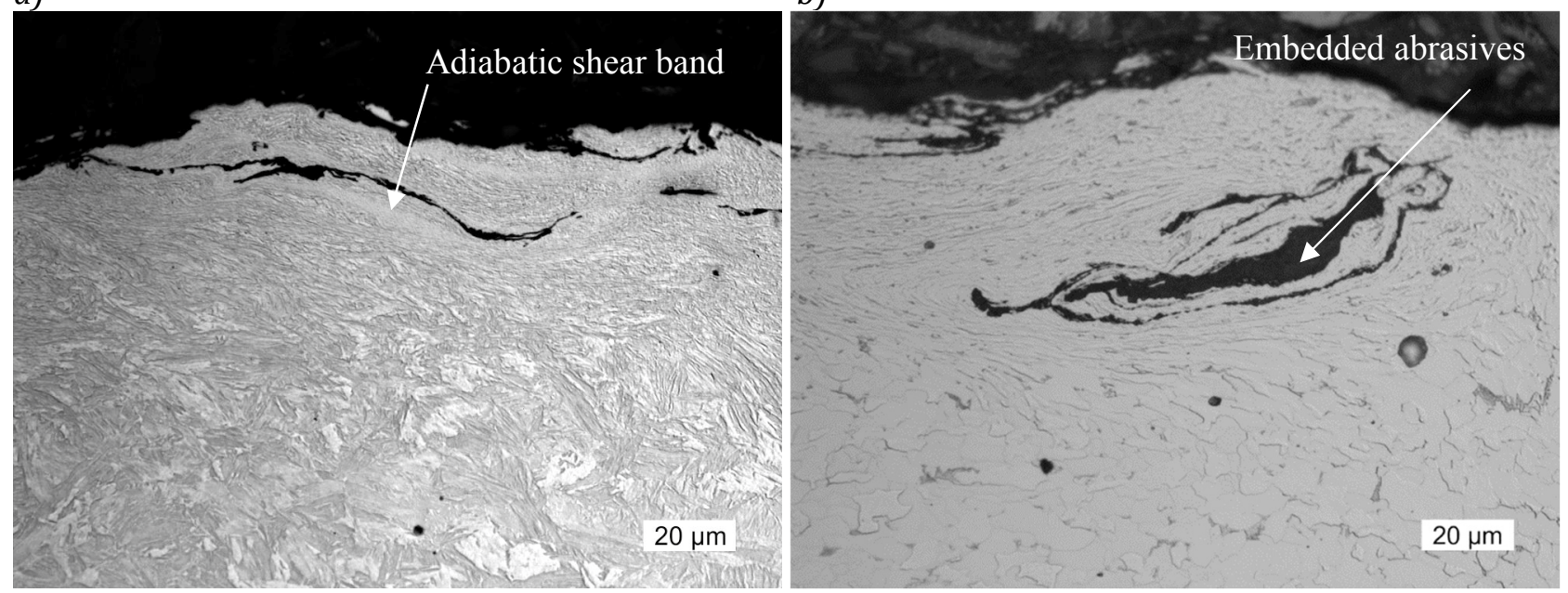

c)

d)

Figure 6. Optical micrographs of the wear surface cross-sections of the 400HB steel samples tested with a) uniaxial crusher, b) crushing pin-on-disc, and c) impeller-tumbler, and d) S355 tested with crushing pin-ondisc.

\section{CONCLUSIONS}

Three different abrasive and impact-abrasive test methods were used to simulate the wear in a wear plate of a dumper truck body. The study included thorough characterization of the wear surfaces and cross-sections of the samples. The following conclusions could be drawn:

- In an optimal case, the comparison of different test methods should be done both against reference material data and by using the true wear areas and contact times in the evaluations. Moreover, it is important that the wear mechanisms be evaluated by characterization.
- Normalization of the test results by reference data does not reveal the differences in the wear rates between the test methods so well, but it is a suitable method for the comparison of materials.

- Thorough characterization of the wear surfaces and cross-sections is essential, when comparing the test methods with each other or with the in-service cases. 
- Based on the characterization results, the three studied wear test methods simulated reasonable well the different wear mechanisms active in the dumper truck wear plate, only missing the formation of the white layers.

\section{ACKNOWLEDGEMENTS}

This work was done within the DIMECC BSA (Breakthrough Steels and Applications) Programme. We gratefully acknowledge the financial support from the Finnish Funding Agency for Innovation and the participating companies.

\section{REFERENCES}

[1] Blickensderfer R, Tylczak JH. Laboratory tests of spalling, breaking, and abrasion of wear-resistant alloys used in mining and mineral processing. Bureau of Mines Report of Investigations 1985, $17 \mathrm{p}$. https://stacks.cdc.gov/view/cdc/10564/cd c 10564_DS1.pdf

[2] Sare IR, Constantine AG. Development of methodologies for the evaluation of wearresistant materials for the mineral industry. Wear 1997;203-204:671-8. https://doi.org/10.1016/S00431648(96)07398-X

[3] Blau PJ. How common is the steadystate? The implications of wear transitions for materials selection and design. Wear 2014;332-333:1120-8. https://doi.org/10.1016/j.wear.2014.11.01 $\underline{8}$
[4] Valtonen K. Relevance of laboratory wear experiments for the evaluation of inservice performance of materials. Tampere University of Technology, 2018. http://urn.fi/URN:ISBN:978-952-154244-2

[5] Ratia V, Valtonen K, Kemppainen A, Kuokkala V-T. High-stress abrasion and impact-abrasion testing of wear resistant steels. Tribol Online 2013;8:152-61. https://doi.org/10.2474/trol.8.152

[6] Valtonen K, Keltamäki K, Kuokkala V-T. High-stress abrasion of wear resistant steels in the cutting edges of loader buckets. Tribol Int 2018;119:707-20. https://doi.org/10.1016/j.triboint.2017.12. $\underline{013}$

[7] Dommarco R, Galarreta I, Ortíz H, David $\mathrm{P}$, Maglieri G. The use of ductile iron for wheel loader bucket tips. Wear 2001;249:100-7.

https://doi.org/10.1016/S00431648(01)00531-2

[8] Abbasi E, Luo Q, Owens D. Case study: Wear mechanisms of NiCrVMo-steel and CrB-steel scrap shear blades. Wear 2018;398-399:29-40.

https://doi.org/10.1016/j.wear.2017.11.01 $\underline{4}$ 